\title{
PREVALÊNCIA DE DTM EM ATLETAS LUTADORES
}

Fernanda WANDEMBRUCK, Felipe MUSSI, Danielle VEIGA BONOTTO, Eli NAMBA, Paulo Afonso CUNALI, Edvaldo ROSA, Daniel BONOTTO

As desordens da articulação temporomandibular são consideradas alterações heterogêneas do grupo psico-fisológico e por esta razão são um dos tópicos mais controversos da clínica odontológica (VANDERAS, PAPAGIANNOULIS, 2002). O número de pacientes com disfunção da articulação temporomandibular tem crescido e as queixas principais são estalidos, dor na região da articulação e limitação da função oral. Atividades desportivas podem gerar forças de grande intensidade e freqüência sobre o sistema mastigatório e, estudos tem havido um crescimento aparente no número de traumas relacionados aos esportes (DAVIDSON, TAUNTON, 1987). Neste contexto, foram avaliados 24 lutadores da seleção brasileira de karatê, com idade entre 18 a 45 anos, com objetivo de avaliar a prevalência de DTM por meio do índice RDC/TMD. Os resultados mostraram que 20,83\% dos indivíduos apresentaram DTM muscular, e 37,5\% deslocamento de disco articular. Conclui-se que a alta prevalência de DTM nos atletas avaliados serve de alerta para a especialidade de DTM e DOF estar atenta a esse grupo de risco.

Palavras-Chave: Articulação Temporomandibular; prevalência; atletas 